\title{
Waste-Free Animal Agriculture that Co-Produces Biogas Energy and Organic Fertilizer: A Holistic Approach
}

\author{
Jason Shih ${ }^{1}$ \\ ${ }^{1}$ North Carolina State University College of Agriculture and Life Sciences
}

December 30, 2020

\begin{abstract}
A novel anaerobic digester system called Holistic DigesterTM System (HDS) was developed. The pilot prototype was constructed and tested twice (4 months each) at the NCSU Field Laboratory for raising 60 feeder pigs to market age for each test. The structure and operation of HDS, the performance of live animal growth, chemical analyses of biogas and the resulting digestate, and the production of a potential organic fertilizer, are presented in this communication. It was concluded that: 1) this operation demonstrated the feasibility of HDS with live animals on farm; 2) daily biogas (approximately $50 \%$ methane) was produced consistently during each of the two studies; 3 ) animals grew well in the modified house with a pit for manure slurry collection. The weight gain of the pigs and feed conversion rate met the top $25 \%$ of the industrial average; and 4) the liquid digestate of the primary digester flowed into the secondary digester preloaded with dry switchgrass, which absorbed the liquid and incubated into a final product. Chemical analysis indicated that NPK values were retained and enriched in the final product, potentially, an organic fertilizer. The new prototype HDS that co-produces biogas and organic fertilizer was successfully tested and, furthermore, HDS left no waste nor wastewater on farm. It is believed that HDS will not only improve the cyclic bioeconomy, but also enforce the environmental and economic sustainability of animal agriculture.
\end{abstract}

\section{Hosted file}

HDS Manuscript - Submitted version.pdf available at https://authorea.com/users/386131/ articles/501376-waste-free-animal-agriculture-that-co-produces-biogas-energy-andorganic-fertilizer-a-holistic-approach 